\title{
Editorial
}

\section{Pigmentation Markers: More Color in the Picture of Uremic Toxicity?}

\author{
R. Vanholder G. Glorieux I. Devolder S. Van Laecke \\ Nephrology Section, University Hospital, Ghent, Belgium
}

The retention of solutes during kidney failure gives rise to a complex pattern of accumulation. In 2003, the uremic compounds which until then had been described in the peer-reviewed literature were tabulated by the European Uremic Toxin Work Group and a total number of 90 different compounds were listed [1]. In the meantime, several other compounds have been identified [2], and the results obtained with proteome analysis, describing more than 1,000 peptidic compounds with a molecular weight of $>800 \mathrm{Da}$, in ultrafiltrates from hemodialysis patients [3] infer that what we currently know in fact reveals only the tip of the iceberg.

To enable the identification of toxicity pathways and to develop therapeutic strategies for the removal of relevant toxic solutes or to counteract their metabolic effects, knowledge on uremic retention must be as complete as possible.

In this issue of Blood Purification, pigmentation markers or melanins, previously unknown as retention solutes, are added as a new set of uremic compounds to the existing list of known uremic toxins [1] by Murakami et al. [4]. At the same time the authors offer information related to one of the most intriguing but insufficiently explained epiphenomena of the uremic syndrome: hyperpigmentation from which many patients with chronic kidney disease suffer $[5,6]$. Recent nephrological literature pays virtually no attention to this problem.
The results reported by Murakami et al. [4] should be considered with care as they are based on only 16 hemodialysis patients and, therefore, need confirmation; of note, 6 of these patients were diabetics, who are known to suffer from an exponential degree of oxidative stress as compared to non-diabetic chronic kidney failure patients. This is a matter of concern since most of the solutes depicted in their article are the result of oxidative modifications. For this reason, when larger populations are studied for the concentration of these solutes, it would be interesting to compare diabetics with non-diabetics.

Apart from their link to melanoma [7] and skin and hair pigmentation $[8,9]$, there is only scant information about the clinical and biochemical significance of these pigmentation markers, but a number of features referred to in the article by Murakami et al. [4] are nevertheless striking, especially for those interested in uremic toxicity and the therapeutic options for fighting this condition. Basically, four reflections come to mind.

First, as metabolites of tyrosine, these molecules have family ties with other groups of uremic retention compounds, most of all the phenols, which also originate from tyrosine [10]. In addition, the structural similitude of eumelanin with dihydroxyindole [11] also suggests a tie with another group of important uremic retention solutes, the indoles. Common features of all these categories of molecules are their protein binding and the difficulty of removing them by standard dialysis therapies.

\begin{tabular}{ll}
\hline KARGER & $\odot$ 2007 S. Karger AG, Basel \\
Fax +4161306 1234 & 0253-5068/07/0256-0480\$23.50/0 \\
$\begin{array}{l}\text { E-Mail karger@karger.ch } \\
\text { www.karger.com }\end{array}$ & $\begin{array}{l}\text { Accessible online at: } \\
\text { www.karger.com/bpu }\end{array}$
\end{tabular}

Raymond Vanholder

Nephrology Section, Department of Internal Medicine, University Hospital, 0K12 De Pintelaan, 185

BE-9000 Gent (Belgium)

Tel. +32 9240 4525, Fax +32 9240 4599, E-Mail raymond.vanholder@ugent.be 
Second, generation of several of the members of this group, e.g. eumelanin, protein-bound 3,4-dihydroxyphenylalanine and 5-S-cysteinyldopa [11-13], is the result of oxidative processes. Since a large fraction of uremic patients, especially those on dialysis, suffer from a protracted micro-inflammatory state [14] resulting in oxidative free radical production [15], the generation of several of the pigmentation markers is thus facilitated by the uremic condition, and this sequence of events might by itself be a suitable explanation for a large proportion of hyperpigmentation observed in chronic kidney disease. Hence, if the held hypothesis is correct, hyperpigmentation could be avoided by eradicating or discouraging any inflammation-generating condition, such as chronic sources of infection like periodontitis, the use of central vein catheters, the application of bio-incompatible dialysis membranes, and/or contact with bacteriologically contaminated dialysis water. With the link to inflammation in mind, it is a bit unfortunate that Murakami et al. [4] did not assess any correlation with inflammatory parameters such as C-reactive protein or cytokine levels.

One might consider the possibility that pigmentation markers could be used as indicators of oxidative stress in uremia. Studies in this context might offer useful information. One should, however, be conscious of the fact that the concentration of these compounds not only depends on oxidation, but also on (lack of) clearance by kidneys and/or dialysis and on the impact of ultraviolet light on the skin [8], hence creating a potential bias for the use of these compounds as an oxidative marker. In addition, the solutes studied by Murakami et al. [4] cannot be considered as stable chemical structures. Conceivably they are further metabolized to other compounds at unpredictable but often short intervals, partly again by oxidation [16].

Third, one should be concerned about the toxicity of these compounds. Although there is very little information in this regard, what we know points to potentially important toxicity. Some of these pigmentation markers are not only the product of oxidative stress but actually also generate oxidation by themselves. Pheomelanin has been shown to produce free radical species, especially in the presence of UV light [8], but also in its absence [17]. Although less well documented, free 5-S-cysteinyldopa has also been shown to produce oxidative stress, at least in vitro [18]. Oxidative stress in turn causes a host of organic lesions, not the least of which is vascular damage [19]. Consequently, the pigmentation markers should be added to the list of compounds potentially linked to cardiovascular disease [20], one of the most important causes of morbidity and mortality in chronic kidney disease. Of note, another metabolite of tyrosine, $\mathrm{p}$-cresylsulfate, has also been shown to induce activation of leukocyte metabolic function [21]. Furthermore, pheomelanin has also been linked to carcinogenic effects [22, 23]. Finally, since the melanins are chemically related to the catecholamines because the structural parts of several of them contain dopamine, one might wonder whether they do not have vasoactive effects as well.

Fourth, while some of these compounds even show a rise in concentration in the presence of presumed molecular weights in the range of approximately $200 \mathrm{Da}$, the fact that most of them are barely removed by dialysis points in the direction of strong protein binding. In this way, another set of molecules is added to the already impressive group of protein-bound molecules [1]. Of note, dialytic removal of protein-bound molecules appears to be difficult, even with highly efficient methods such as high-flux dialysis [24] and probably intensive convection should be added to allow some removal [25]. Difficult removal by dialysis also was a feature of the majority of solutes submitted to evaluation in the study by Murakami et al. [4].

The relevance of the article by Murakami et al. [4] is essentially related to the fact that it is the first report on an interesting group of potential uremic toxins about which the future may shed more light on their relative importance. Further research will be needed, however, to classify this group at its real value among the other uremic retention solutes. In this research several relevant questions should be answered: (1) Do these molecules indeed induce oxidative stress in vitro and in vivo? (2) Do they still have other biological/toxic effects? In this area special interest may exist in the evaluation of the effect on the vessel wall, both acutely (vasoconstriction) and chronically (wall thickening and stiffness). (3) What is their kinetic behavior during application of different modes of renal replacement therapy? (4) Are there ways to enhance their removal or restrain their generation? (5) Is their concentration related to inflammatory markers, vascular quality and/or patient outcome? (6) Can their concentration and/or toxic impact be influenced by antioxidants such as $\mathrm{N}$-acetylcysteine or vitamin $\mathrm{C}$ or $\mathrm{E}$ ?

The article by Murakami et al. [4] generates the first momentum in the direction of this broader evaluation. 


\section{References}

1 Vanholder R, De Smet R, Glorieux G, et al: Review on uremic toxins: classification, concentration, and interindividual variability. Kidney Int 2003;63:1934-1943.

2 Meert N, Schepers E, De Smet R, et al: Inconsistency of reported uremic toxin concentrations. Artif Organs 2007;31:600-611.

3 Weissinger EM, Kaiser T, Meert N, et al: Proteomics: a novel tool to unravel the pathophysiology of uraemia. Nephrol Dial Transplant 2004;19:3068-3077.

4 Murakami K, Wakamatsu K, Nakanishi Y, Takahashi H, Sugiyama S, Ito S: Serum levels of pigmentation markers are elevated in patients undergoing hemodialysis. Blood Purif 2007;25:483-489.

5 Bencini PL, Montagnino G, Citterio A, et al: Cutaneous abnormalities in uremic patients. Nephron 1985;40:316-321.

6 Lai CF, Kao TW, Tsai TF, et al: Quantitative comparison of skin colors in patients with ESRD undergoing different dialysis modalities. Am J Kidney Dis 2006;48:292-300.

7 Riley PA: Melanogenesis and melanoma. Pigment Cell Res 2003;16:548-552.

8 Takeuchi S, Zhang W, Wakamatsu K, et al: Melanin acts as a potent UVB photosensitizer to cause an atypical mode of cell death in murine skin. Proc Natl Acad Sci USA 2004;101:15076-15081.

9 Kongshoj B, Thorleifsson A, Wulf HC: Pheomelanin and eumelanin in human skin determined by high-performance liquid chromatography and its relation to in vivo reflectance measurements. Photodermatol Photoimmunol Photomed 2006;22:141-147.

10 Evenepoel P, Claus D, Geypens B, et al: Evidence for impaired assimilation and increased colonic fermentation of protein, related to gastric acid suppression therapy. Aliment Pharmacol Ther 1998;12:10111019 .
11 Ito S: The IFPCS presidential lecture: a chemist's view of melanogenesis. Pigment Cell Res 2003;16:230-236.

12 Sutherland WH, Gieseg SP, Walker RJ, et al: Serum protein-bound 3,4-dihydroxyphenylalanine and related products of protein oxidation and chronic hemodialysis. Ren Fail 2003;25:997-1009.

13 Ito S, Jimbow K, Kato T, Kiyota M, Fujita K: Protein-bound dopa and 5-S-cysteinyldopa in non-melanogenic tissues. Acta Derm Venereol 1983;63:463-467.

14 Stenvinkel P, Heimburger O, Lindholm B, Kaysen GA, Bergstrom J: Are there two types of malnutrition in chronic renal failure? Evidence for relationships between malnutrition, inflammation and atherosclerosis (MIA syndrome). Nephrol Dial Transplant 2000;15:953-960.

15 Nguyen-Khoa T, Massy ZA, De Bandt JP, et al: Oxidative stress and haemodialysis: role of inflammation and duration of dialysis treatment. Nephrol Dial Transplant 2001;16: 335-340.

16 Davies MJ, Fu S, Wang H, Dean RT: Stable markers of oxidant damage to proteins and their application in the study of human disease. Free Radic Biol Med 1999;27:11511163

17 Ye T, Hong L, Garguilo J, et al: Photoionization thresholds of melanins obtained from free electron laser-photoelectron emission microscopy, femtosecond transient absorption spectroscopy and electron paramagnetic resonance measurements of oxygen photoconsumption. Photochem Photobiol 2006; 82:733-737.
18 Spencer JP, Whiteman M, Jenner P, Halliwell B: 5-s-Cysteinyl-conjugates of catecholamines induce cell damage, extensive DNA base modification and increases in caspase-3 activity in neurons. J Neurochem 2002;81: 122-129.

19 Tesfamariam B, DeFelice AF: Endothelial injury in the initiation and progression of vascular disorders. Vascul Pharmacol 2007;46: 229-237.

20 Vanholder R, Massy Z, Argiles A, et al: Chronic kidney disease as cause of cardiovascular morbidity and mortality. Nephrol Dial Transplant 2005;20:1048-1056.

21 Schepers E, Meert N, Glorieux G, et al: P-cresylsulphate, the main in vivo metabolite of p-cresol, activates leucocyte free radical production. Nephrol Dial Transplant 2007;22: 592-596.

22 Hill HZ, Hill GJ: UVA, pheomelanin and the carcinogenesis of melanoma. Pigment Cell Res 2000;13(suppl 8):140-144.

23 Menon IA, Persad S, Ranadive NS, Haberman HF: Effects of ultraviolet-visible irradiation in the presence of melanin isolated from human black or red hair upon Ehrlich ascites carcinoma cells. Cancer Res 1983;43: 3165-3169.

24 Lesaffer G, De Smet R, Lameire N, et al: Intradialytic removal of protein-bound uraemic toxins: role of solute characteristics and of dialyser membrane. Nephrol Dial Transplant 2000;15:50-57.

25 Meert N, Beerenhout C, De Smet R, Kooman J, Vanholder R: Removal of protein-bound uremic solutes by predilution on-line hemofiltration (abstract). J Am Soc Nephrol 2004; 15:363A. 